\title{
A cost-benefit algorithm for rapid diagnosis of tuberculosis and rifampicin resistance detection during mass screening campaigns
}

\author{
Valerie Flore Donkeng-Donfack ${ }^{1 *} \mathbb{D}$, Jules Brice Tchatchueng-Mbougua ${ }^{2}$, Ngu Njei Abanda', \\ Suzanne Magloire Ongboulal' ', Yvonne Josiane Djieugoue', Yannick Kamdem Simo', \\ Micheline Mekemnang Tchoupa ${ }^{3}$, Frédéric Bekang Angui ${ }^{3}$, Albert Kuate Kuate ${ }^{3}$, Vincent Mbassa ${ }^{3}$, \\ Edwige Mvondo Abeng Belinga ${ }^{3}$ and Sara Eyangoh'
}

\begin{abstract}
Background: Active tuberculosis (TB) case finding is important as it helps detect pulmonary TB cases missed by the other active screening methods. It requires periodic mass screening in risk population groups such as prisoners and refugees. Unfortunately, in these risk population groups periodic mass screening can be challenging due to lengthy turnaround time (TAT), cost and implementation constraints. The aim of this study was to evaluate a diagnostic algorithm that can reduce the TAT and cost for TB and Rifampicin resistance (RR) detection. The algorithm involves testing with TB-LAMP followed by Xpert MTB/RIF for positive TB-LAMP cases to diagnose TB during mass campaigns in prisons and refugee camps.
\end{abstract}

Methods: The National Tuberculosis Control Program (NTCP) organized routine TB mass-screening campaigns in 34 prisons and 3 villages with refugees camps in Cameroon in 2019. TB LAMP was used for initial TB diagnosis and all TB-LAMP positive cases tested with the Xpert MTB/RIF assay to determine RR. TAT and cost benefits analysis of the combined use of TB-LAMP and Xpert MTB/RIF assays was determined and compared to the Xpert MTB/RIF assay when used only.

Results: A total of 4075 sputum samples were collected from TB presumptive, 3672 cases in 34 prisons and 403 samples in 3 villages. Of the 4,075 samples screened with TB-LAMP, 135 were TB positive (3.31\%) and run on the Xpert MTB/RIF. Of the 135 positives cases, Xpert MTB/RIF revealed 3 were RR (2.22\%). The use of TB-LAMP followed by testing with Xpert MTB/RIF for TB and RR detection reduced the TAT by $73.23 \%$ in prisons and $74.92 \%$ in villages. In addition to a reduced TAT, the two molecular tests used in synergy is cost benefit from year 2 onwards.

Conclusion: This study demonstrates the advantages of a diagnostic algorithm based on an initial testing with TBLAMP followed by testing with Xpert MTB/RIF for TB diagnosis. This approach improved early and rapid TB detection with an added advantage of providing RR status. The proposed algorithm is effective and less costly from the second year of implementation and should be used by TB control programs.

\footnotetext{
*Correspondence: donkeng@pasteur-yaounde.org

${ }^{1}$ Mycobacteriology Unit, National Tuberculosis Reference Laboratory,

Centre Pasteur du Cameroun, P.O. 1274, Yaoundé, Cameroon

Full list of author information is available at the end of the article
}

(C) The Author(s) 2022. Open Access This article is licensed under a Creative Commons Attribution 4.0 International License, which permits use, sharing, adaptation, distribution and reproduction in any medium or format, as long as you give appropriate credit to the original author(s) and the source, provide a link to the Creative Commons licence, and indicate if changes were made. The images or other third party material in this article are included in the article's Creative Commons licence, unless indicated otherwise in a credit line to the material. If material is not included in the article's Creative Commons licence and your intended use is not permitted by statutory regulation or exceeds the permitted use, you will need to obtain permission directly from the copyright holder. To view a copy of this licence, visit http://creativecommons.org/licenses/by/4.0/. The Creative Commons Public Domain Dedication waiver (http://creativeco mmons.org/publicdomain/zero/1.0/) applies to the data made available in this article, unless otherwise stated in a credit line to the data. 
Keywords: TB-LAMP, Xpert MTB/RIF, Algorithm, Screening, Mass campaigns, Prisons, Refugee camps, Costeffectiveness

\section{Background}

Tuberculosis (TB) is a leading cause of morbidity and mortality worldwide. Each year, an estimated 10 million people develop TB, and another 1.5 million die from TB [1]. TB unequally affects certain population groups such as prisoners and refugees that have limited access to health care [2-4]. The crowded living conditions of most prisons and refugee villages facilitate TB transmission [5-8]. In Addition, prisons also serve as an optimal environment for the transmission of TB to the general population through prison staff, visitors and released inmates [9]. In Cameroon, the prevalence of TB is largely unknown but estimated to be about 3500 per 100,000 prisoners [10]. Conversely, the annual TB incidence in prisons is 1700 per 100,000 prisoners and it is about 10 times higher than those of the general population (186 per 100,000 population) [11]. The burden of TB within refugee camps is rarely reported or unknown. However, according to a 2020 National TB survey, the incidence of $\mathrm{TB}$ in villages in close proximity to refugee camps in the East region of Cameroon was estimated at 25 per 100,000 population [10].

In response to the burden of TB in prisons and refugee camps, The National Tuberculosis Control Program of (NTCP) of Cameroon, introduced several strategies to reduce transmission. Among which, the active screening of prisoners and refugees with presumptive pulmonary TB (PTB). Active screening entails systematic screening for TB signs and symptoms at point of entry, contact tracing of exposed cases and periodic mass screenings $[13,14]$. Periodic mass screening in prisons is extremely important as it helps to detect PTB cases missed by the other active screening methods. Unfortunately, periodic mass screening can be challenging and difficult to sustain due to high cost and implementation constraints [14, 15] such as overcrowded facilities, high number of sputum samples and limited laboratory capacity to process high number of samples. These implementation challenges could be mitigated by the use of highly sensitive, rapid, and cheap diagnostic kits. Molecular-based TB diagnostic kits such as Xpert $^{\circledR}$ MTB/RIF (Cepheid, Sunnyvale USA) and TB-LAMP (Eiken Chemical, Tokyo Japan) provides such convenience. However, there is very little evidence to guide policymakers on the relative costeffectiveness and benefits of using these tests for mass screening across prison facilities. The Xpert MTB/RIF assay uses real-time polymerase chain reaction technology to detect MTB and rifampicin resistance (RR). The
Xpert MTB/RIF assay, requires minimal expertise, and has a short turnaround time (TAT) of two hours to confirm MTB and detect rifampicin resistance [16]. The Xpert MTB/RIF assay is recommended by WHO since 2010 [17] and has been in used in Cameroon since 2012 with excellent performance. WHO has endorsed TBLAMP in 2016 [18] and it has been implemented in Cameroon in 2017. TB-LAMP has a TAT of one hour, is easy to use, results are easy to interpret but it does not detect rifampicin resistance $[18,19]$. According to several studies, including one conducted in Cameroon, TB-LAMP and Xpert MTB/RIF displayed similar sensitivity and specificity [18-21]. In this study, we sought to evaluate if a diagnostic algorithm based on an initial testing with TB-LAMP followed by testing with Xpert MTB/RIF to diagnose TB could reduce the TAT and be cost-beneficial during mass campaigns in prisons and in refugee camps compared to Xpert MTB/RIF when used alone.

\section{Methods}

\section{Study setting and population}

Cameroon is a central African country with a prison population of about 30,701 inmates. There are about 79 functional prisons spread-out across the country [22]. There are also several refugees' camps in the Eastern and Northern regions of Cameroon where displaced people from neighboring countries are settled. Most of these camps are within local villages.

In 2016 Cameroon's NTCP launched its first TB mass screening campaign targeting just one prison. By 2018, the NTCP was able to do mass screening for TB in all prisons. During the 2018 mass screening, 2428 samples were collected, and Xpert MTB/RIF assay was used for bacteriological analysis. The four-module Xpert MTB/ RIF instrument was used with an testing capacity of 12-16 samples/day [23]. Using this Xpert MTB/RIF equipment, results were not timely and patient care was extensively delayed. In addition, samples were of poor quality as adequate storage conditions were non-existent. To speed up the diagnostic turnaround time, for the 2019 mass screening campaign, the NTCP recommended the use of TB-LAMP for initial testing of samples and then Xpert MTB/RIF to test the presence of resistance in TBLAMP positive cases. With TB-LAMP, 14 specimens are processed in one run and about 70 or more samples can be processed per day [24]. As such, we sought to determine the TAT and cost of using this new diagnostic 
algorithm of TB-LAMP and Xpert MTB/RIF for the mass screening of $\mathrm{TB}$ at prisons and refugee camps.

\section{Data collection}

In this study, we used TB mass screening data from 34 prisons and 3 villages with refugee camp in the eastern region of Cameroon that is Tongo-Gandima, Quamy and Ndokayo. During mass screening for TB, all inmates or refugees were screened for symptoms of TB such as persistent cough, weight loss, night sweats and high temperature. For each presumptive case, a questionnaire was used to record demographic information and symptoms. After this, a sputum sample was collected for bacteriological analysis. All sputum samples were transported to the closest designated TB diagnostic laboratory. Nine selected TB laboratories were involved, amongst which, 06 were equipped with TB-LAMP and Xpert MTB/RIF instruments (Diagnosis and Treatment Centers (DTCs). These were the DTCs of Ngaoundere and Maroua, the Regional TB laboratory of Bertoua, the Regional Reference Laboratory of Garoua, the Regional Reference Laboratory of Douala and the National Reference Laboratory (NRL-TB) hosted by Centre Pasteur du Cameroun.). Two DTCs were equipped with the TB-LAMP alone (DTCs of Ebolowa and Mbalmayo), and one was equipped with Xpert MTB/RIF alone (DTC of Ambam). The 02 laboratories equipped with only TB-LAMP (Ebolowa and Mbalmayo) were responsible for sending positives samples to Ambam and Centre Pasteur du Cameroun, respectively.

\section{Sample collection and transportation}

A sputum sample of about $3 \mathrm{ml}$ was collected from each presumptive TB case. In larger prison facilities, sample collection could occur over several days with about 150 samples collected per day. Collected samples were placed in a cold box and transported on the same day to the designated laboratory. Once at the laboratory, samples were stored at $+4{ }^{\circ} \mathrm{C}$ until the next day for testing.

\section{Laboratory tests}

At the laboratory, all samples were initially tested with TB-LAMP and only TB-LAMP positive samples were subsequently tested with Xpert MTB/RIF assay to detect rifampicin resistance. Both tests were performed according to the manufacturer's (Eiken and Cepheid, respectively) instructions $[17,18]$. Briefly, for the TBLAMP assay, $60 \mu \mathrm{L}$ of sputum sample was pipetted into a heating tube and incubated at $90{ }^{\circ} \mathrm{C}$ for $5 \mathrm{~min}$. The purified DNA was eluted from the absorbent tube and transferred into the injection cap. After mixing with lyophilized reagents, the amplification mixture was incubated at $67{ }^{\circ} \mathrm{C}$ for $40 \mathrm{~min}$. The final results were interpreted using ultraviolet fluorescence detection. The TAT of TB-LAMP was $60 \mathrm{~min}$, and no more than 14 specimens were processed per batch [19]. For the Xpert MTB/RIF assay, sample reagent was added in a 1:2 ratio to $2 \mathrm{ml}$ of sample. The closed tube was manually agitated twice followed by a 15-min incubation period at room temperature prior to transferring $2 \mathrm{ml}$ of the inactivated sample to the Xpert test cartridge. Cartridges were inserted into the four-module GeneXpert MTB/RIF instrument and the automatically generated results were read after $90 \mathrm{~min}[17,23]$.

\section{Assessment of costs}

We used the ingredient cost method as described by Levin and McEwan (2001) [24] to estimate the costing of each testing algorithms. Briefly and as shown in Additional file 1: Tables S6-S9, We itemized the resources for each algorithm and obtained their respective market prices obtained from manufacturers and available in published literature.

The remunerations of key personnel directly involved in the mass screening were obtained from the NTP. This assessment include maintenance cost through warranty extension for TB-LAMP and Xpert MTB/ RIF (4-Module System). The training cost take in account for TB-LAMP and Xpert MTB/RIF was not included. Such cost is usually covered by the National

Table 1 Cost estimate (USD) per algorithm and per population for 3 years

\begin{tabular}{|c|c|c|c|c|c|c|}
\hline & \multicolumn{5}{|c|}{ Cost estimate (USD) per algorithm and per population } & \\
\hline & \multicolumn{3}{|l|}{ Prisons } & \multicolumn{3}{|l|}{ Villages } \\
\hline & Year 1 & Year 2 & Year 3 & Year 1 & Year 2 & Year 3 \\
\hline Algorithm 1: Testing with Gene Xpert MTB/RIF & 87591.21 & 74237.89 & 84089.58 & 26284.13 & 7547.75 & 11208.91 \\
\hline $\begin{array}{l}\text { Algorithm 2: Initial testing with TB-LAMP followed } \\
\text { by testing with Xpert MTB/RIF }\end{array}$ & 87507.41 & 57287.24 & 64596.33 & 29944.11 & 5670.38 & 9049.94 \\
\hline Difference Cost between algorithm 2 and 1 & 83.80 & 16934.43 & 19474.59 & -3659.98 & 1877.36 & 2158.97 \\
\hline
\end{tabular}


Tuberculosis Program through various bilateral agreements of which the cost is rarely disclosed or when disclosed vary extensively.

The cost benefit of TB diagnosis during mass screening campaign was estimated for 03 consecutive years and calculated by the difference between the cost using only Xpert MTB/RIF assays as diagnosis tool and the cost using TB-LAMP and Xpert MTB/RIF assays in combination (Table 1). The items including cost of; equipment, shipment, UPS, printer, air conditioners, consumables (cost per cartridges, losses due to error and incorrect use), maintenance and Human resources (laboratories technicians, nurses, medical doctors, Prison staff, TB Regional coordinators, driver) were considered for cost analysis.

\section{Statistical analysis}

Participants will be described with respect to sociodemographic, clinical and biomedical characteristics. The description will be in terms of median and interquartile range for continuous variables, and using count and percentages for categorical data. The TAT of combined TB-LAMP and Xpert MTB/RIF assay was compared to Xpert MTB/RIF assay alone. To perform this comparison, we calculated the time used to perform TB-LAMP and Xpert MTB/RIF consecutively for initial diagnosis of TB and Rifampicin resistance. We then compared this time to the requested time if Xpert MTB/RIF would have been used only. For the analysis we considered the TAT for each test as the total time required for sample preparation and amplification. We assumed that $96 \mathrm{~min}$ was used for TB-LAMP test to perform a batch of 14 samples and $135 \mathrm{~min}$ for Xpert MTB/RIF test to perform a batch of 04 samples.

\section{Results}

\section{Study population}

A total of 15,699 prisoners and 30,611 villagers were screened. As shown in Fig. 1, there were 3672 presumptive TB cases among prisoners and 403 among villagers. For every presumptive TB case, about $3 \mathrm{ml}$ of sputum samples were collected. The number of samples collected ranged from 27 to 483 depending on the number of prisoners at the prison facility (Table 2 ).

The 3672 presumptive pulmonary TB prison cases were enrolled from 34 prisons in 8 regions of Cameroon and had an average age of 35.4 years (range: $22-62$ ). As presented in Table 3, night sweats was the main clinical symptom observed (52\%) followed by fever in $47.7 \%$ of prison cases. For the three villages (Ndokayo, TongoGandima, Ouamy) in the Eastern region of Cameroon, 403 presumptive pulmonary TB cases were enrolled in the TB mass-screening campaign, the average age was
46.1 years (range: 16-90). The main clinical symptoms observed were chest pain (83.8\%), weight loss (70.1\%), fever $(69.3 \%)$ and dyspnea (57.9\%).

\section{Laboratory performance and turnaround time}

Of the 4075 presumptive TB cases, 135 were laboratory confirmed (3.31\%) of which $123(3.34 \%)$ were prison cases and $12(2.9 \%)$ were village cases (Tables 4,5$)$. Of the $123 \mathrm{~TB}$ prison cases, 03 were RR (2.36\%). The three cases were from two prisons (Nkondengui and Nanga Eboko) in the Centre region (Table 4). The TAT of the new diagnostic algorithm using TB-LAMP as initial diagnosis followed by Xpert MTB/RIF compared to the diagnostic algorithm using Xpert MTB/RIF assay only is presented in Table 2. With 3672 samples, a total of $543.8 \mathrm{~h}$ was used for TB diagnosis with TB-LAMP and Xpert MTB/ RIF assays in combination during TB mass-screening in prison compared to $2053.13 \mathrm{~h}$ for Xpert MTB/RIF alone. Concerning TB mass-screening in villages, 403 samples were analyzed within $57 \mathrm{~h}$ with the help of TB-LAMP and Xpert MTB/RIF assays performed in combination compared to 227.25 for Xpert MTB/RIF only. Our results showed that TAT was reduced to about $73.23 \%$ and $74.92 \%$, respectively for prisons and villages with TBLAMP as initial diagnostic tool followed by Xpert MTB/ RIF.

\section{Benefit-cost analysis}

The use of TB-LAMP as initial diagnostic tool followed by Xpert MTB/RIF for diagnosing TB during mass campaign showed that this algorithm is cost benefit for years 2 and 3. As shown in Table 1, about 16,934 and 19,474 USD are saved for years 2 and 3, respectively in prison and 1877 and 2158 USD are saved for years 2 and 3, respectively in village, respectively.

\section{Discussion}

In this study, we showed that a diagnostic algorithm using TB-LAMP and Xpert MTB/RIF assays during mass screening campaign leads to early availability of diagnostic results and is cost effective. The TAT of using both TB-LAMP and Xpert MTB/RIF assays during TB mass screening was shorter than TAT of using Xpert MTB/RIF assay only. In prison and village campaigns, we observed a $3 / 4$ reduction in the number of hours required for testing the same sample volume. This reduction in the TAT for TB confirmation in laboratory was beneficial as it allowed positive patients to be quickly isolated and placed on treatment. Therefore, this decrease in TAT for detecting MTB and early initiation of treatment would not have been possible if Xpert MTB/ RIF was used only. Fundamentally, the GeneXpert equipment was introduced into clinical practice to expedite 


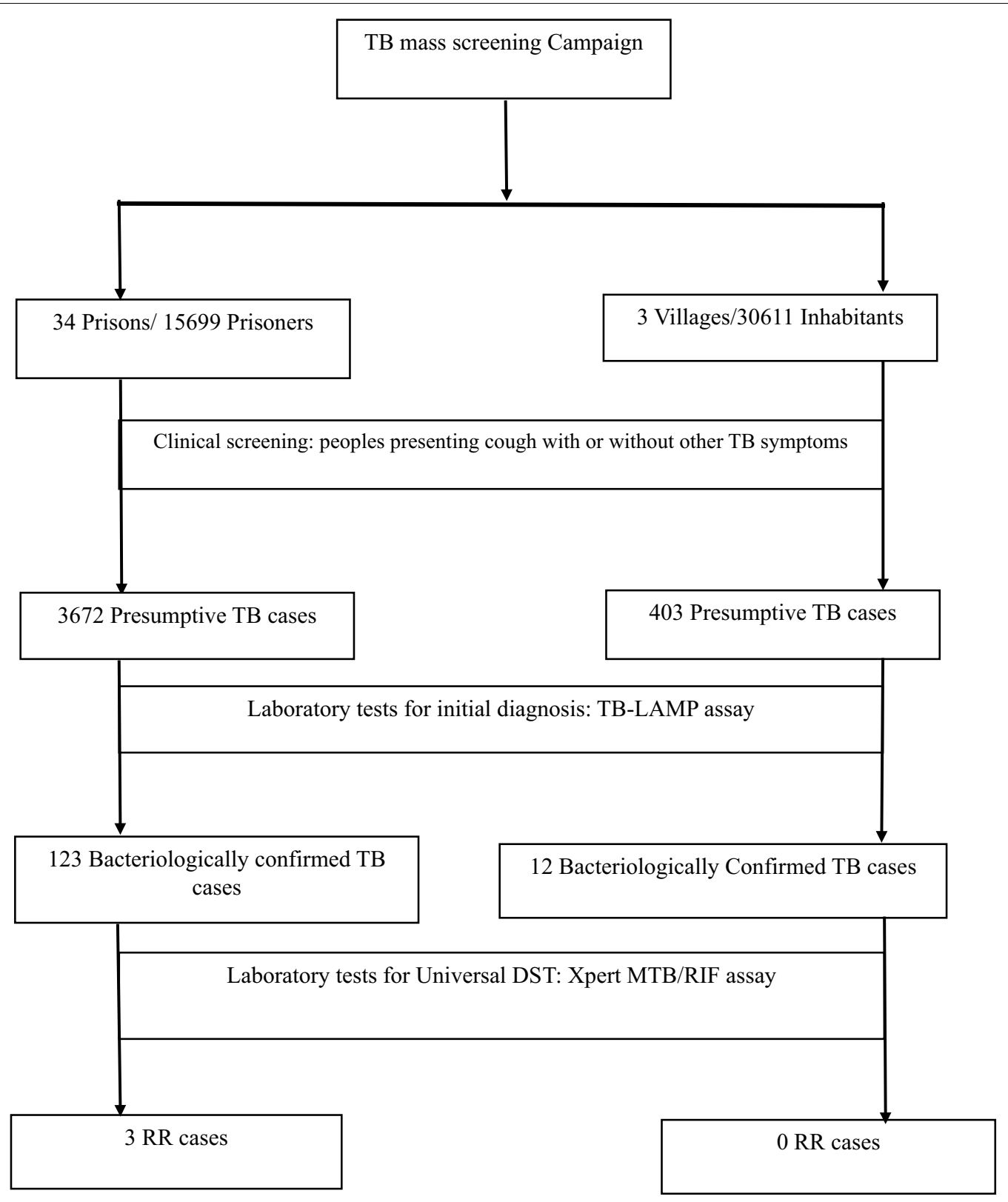

Fig. 1 Flow chart of study design

diagnosis. However in Cameroon, most TB diagnostic facilities are only equipped with the four module GeneXpert system that can process a maximum of 16 samples/ day [17]. When confronted with high sample volumes like during mass screening campaigns, their clinical utility becomes questionable. For example, in 2018, when only the Xpert MTB/RIF equipment was used to test 258 sputum samples from 5 prisons at the Far North region, it took 18 days to complete laboratory analysis of the samples with the four modules instruments GeneXpert equipment. This delayed testing could be worst in laboratories that also uses the GeneXpert equipment to diagnose other diseases such as HIV and Hepatitis C than TB [25]. In such a situation, the priority of using the GeneXpert equipment would be given to the daily samples of the laboratory. Consequently, the delay of processing for samples from TB screening mass campaign could be increased. In addition, for Xpert MTB/RIF analysis, samples should be refrigerated at $2-8{ }^{\circ} \mathrm{C}$ for up to 10 days [17]. However, because of the delay in sample processing, TB laboratories have to store samples at $2-8{ }^{\circ} \mathrm{C}$ for more than 10 days during TB mass screening campaigns. 


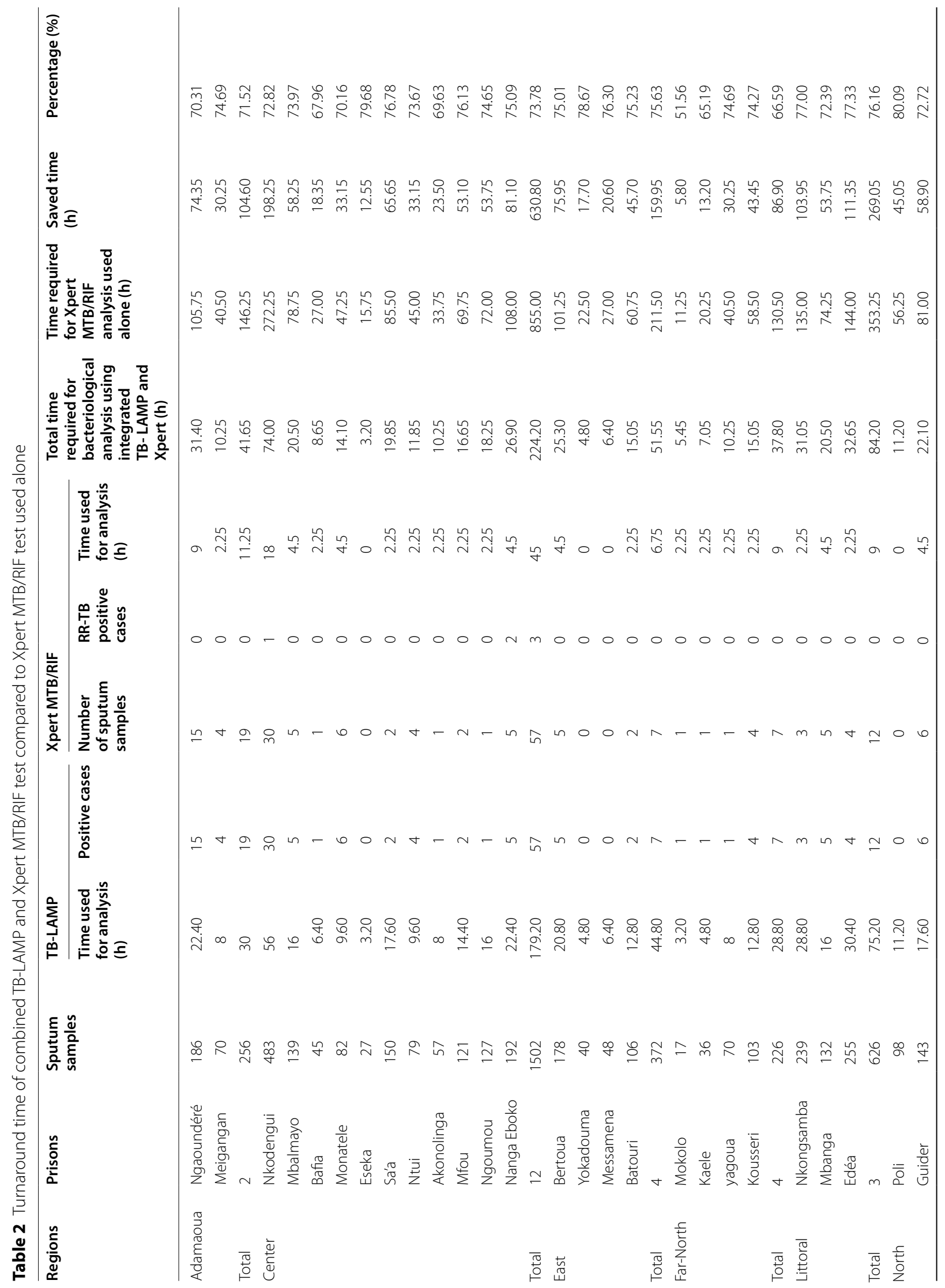




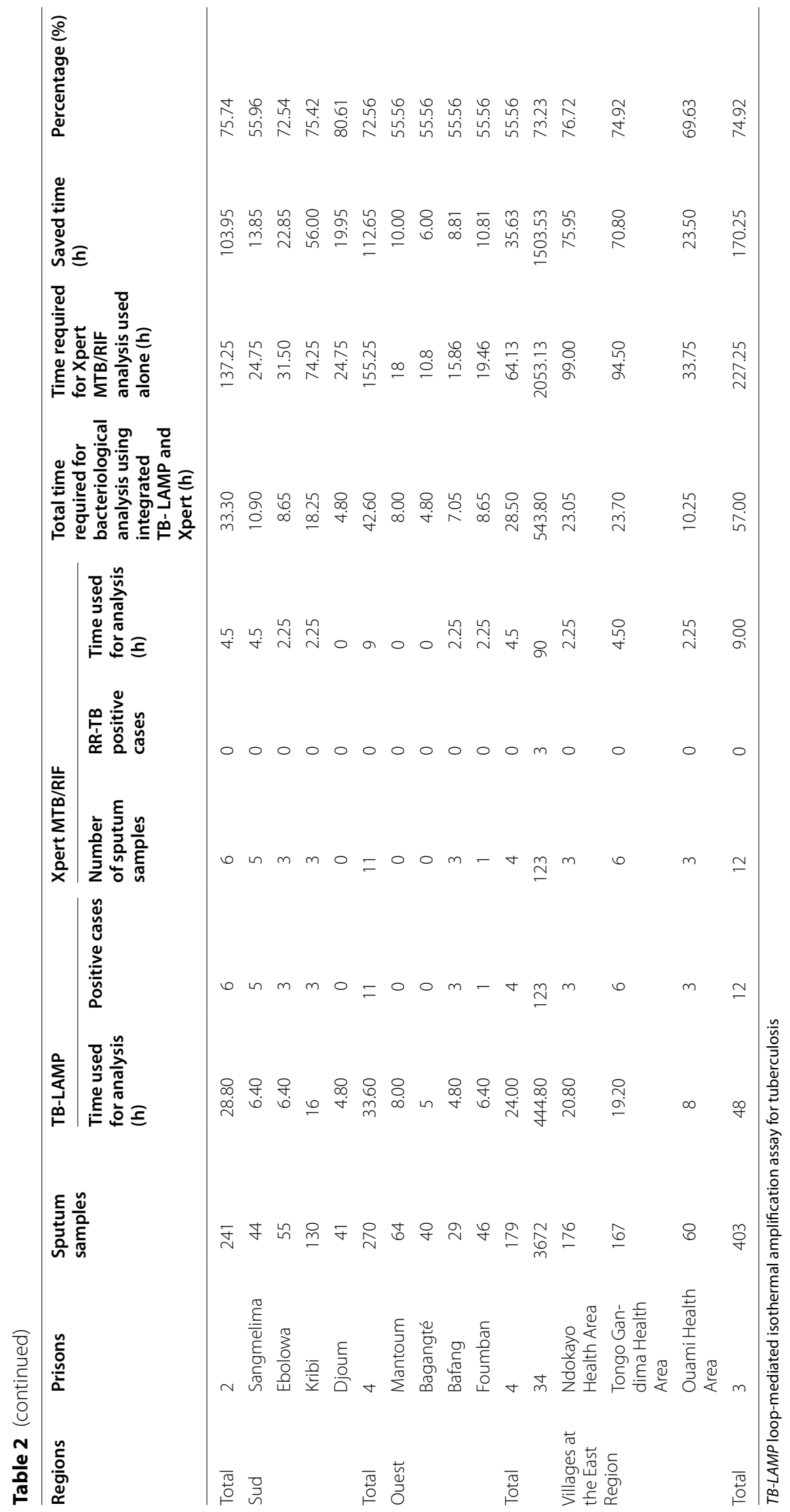


Table 3 Clinical and biomedical characteristics of presumptive cases

\begin{tabular}{lll}
\hline Characteristics & Prisons (N=3672) & Village (N= 403) \\
\hline $\begin{array}{l}\text { Gender } \\
\text { Female }\end{array}$ & $94(2.6 \%)$ & $226(56.1 \%)$ \\
Age in years (mean(min.-max.)) & $35.4(22-62)$ & $46.1(16-90)$ \\
Clinical symptoms & & \\
$\quad$ Cough & $3672(100 \%)$ & $29(7.7 \%)$ \\
Fever & $1752(47.7 \%)$ & $278(69.3 \%)$ \\
Hemoptytis & $813(22.1 \%)$ & $46(11.6 \%)$ \\
Night sweats & $1908(52 \%)$ & $253(63.1 \%)$ \\
Chest pain & - & $337(83.8 \%)$ \\
$\quad$ Dyspnea & $547(14.9 \%)$ & $232(57.9 \%)$ \\
$\quad$ Weight loss & - & $279(70.1 \%)$ \\
Alcohol & $1369(37.3 \%)$ & $64(16 \%)$ \\
Smokers & $1239(33 \%)$ & $10(2.6 \%)$ \\
\hline
\end{tabular}

This extended storage time poses a problem of adequate conservation of samples, questions the quality of those samples at the time of analysis. For this reason, in 2019 after introducing TB-LAMP in Cameroon for TB diagnosis, the NTCP recommended that TB-LAMP be used in combination with Xpert MTB/RIF to shorten the TAT of TB diagnosis during TB mass-screening campaigns that will lead to early treatment.

Our cost analysis of using TB-LAMP and Xpert MTB/ RIF assays in comparison to Xpert MTB/RIF assay shows a cost saving of about 16,934 and 19,474 USD for year 2 and 3 , respectively in prison and 1877 and 2158 USD for year 2 and 3, respectively in village. We used 2019 prices available in the global drug facility catalogue to estimate the cost of the different testing algorithm. That is 9.8 USD for an Xpert MTB/RIF cartridges and 8.60 USD for a TBLAMP test [26] regarding year 1. However, on March
24, 2020, the World TB Day, the Global Drug Facility (GDF) dropped the cost of a TB-LAMP test to 6.0 USD per patient $[27,28]$. Accordingly, we considered the new price of TB-LAMP test (6 USD) for years 2 and 3.

This mass screening in prisons and villages was important as 135 PTB cases that were missed by the passive screening methods were detected. Of the 15,699 prisoners screened 123 were TB positive resulting to a notification rate of $783 / 100000$ inmates. This notification rate is about 4 times higher than the national TB rate $(186 / 100000)(12)$. The higher notification rate could be due to overcrowding and poor ventilation at prison facilities [29]. Concerning villages, of the 30,611 inhabitants screened, 12 were TB positives cases resulting to a notification rate of $40 / 100000$ inhabitants. Although this village notification rate was about 1.6 times higher than that of the East region (25/100000) where the villages are situated [10] and was 4.65 times less than the national TB rate (186/100000) (12). In addition to TB cases detected, 03 RR-TB cases were detected in prisons. This detection rate of $2.36 \%$ amongst prisoners was higher than the estimated national yearly incidence of $1.6 \% \mathrm{RR}-\mathrm{TB}$ among new tuberculosis cases (11). The detection of TB and RR cases supports the utility of mass screening campaigns especially in prison facilities.

According to WHO, Cameroon is not considered as a TB MDR burdened country. As such, our proposed algorithm that first seeks to detect TB cases before testing for RR is adequate, less costly and timely for mass screenings in prisons and villages with refugee camps.

This study is a secondary analysis of the data collected by the NTCP, which represent his main limitation. Two possible consequences derive from this limit; first, the cost estimation analysis did not include a sensitivity and

Table 4 Repartition of presumptive and TB cases in prisons/region

\begin{tabular}{|c|c|c|c|c|c|c|c|c|c|}
\hline Regions & $\begin{array}{l}\text { Number } \\
\text { of } \\
\text { Prisons }\end{array}$ & $\begin{array}{l}\text { Prison } \\
\text { capacity or } \\
\text { number of } \\
\text { inmates }\end{array}$ & $\begin{array}{l}\text { PTB- } \\
\text { Presumptive } \\
\text { cases } \\
\text { TB-LAMP }\end{array}$ & $\begin{array}{l}\text { Percentage } \\
(\%)\end{array}$ & $\begin{array}{l}\text { TB-LAMP } \\
\text { Positive }\end{array}$ & $\begin{array}{l}\text { Percentage } \\
\text { (\%) }\end{array}$ & $\begin{array}{l}\text { TB-LAMP } \\
\text { Positive cases } \\
\text { Xpert MTB/ } \\
\text { RIF }\end{array}$ & $\begin{array}{l}\text { RR Xpert } \\
\text { MTB/RIF }\end{array}$ & Percentage (\%) \\
\hline Adamaoua & 2 & 1729 & 256 & 14.81 & 19 & 7.42 & 19 & 0 & 0.00 \\
\hline Centre & 11 & 7590 & 1502 & 19.79 & 57 & 3.79 & 57 & 3 & 5.26 \\
\hline East & 4 & 1333 & 372 & 27.91 & 7 & 1.88 & 7 & 0 & 0.00 \\
\hline Far-North & 4 & 1619 & 226 & 13.96 & 7 & 3.10 & 7 & 0 & 0.00 \\
\hline Littoral & 3 & 1090 & 626 & 57.43 & 12 & 1.92 & 12 & 0 & 0.00 \\
\hline North & 2 & 589 & 241 & 40.92 & 6 & 2.49 & 6 & 0 & 0.00 \\
\hline South & 4 & 1077 & 270 & 25.07 & 11 & 4.07 & 11 & 0 & 0.00 \\
\hline West & 4 & 672 & 179 & 26.64 & 4 & 2.23 & 4 & 0 & 0.00 \\
\hline Total & 34 & 15699 & 3672 & 23.39 & 123 & 3.35 & 123 & 3 & 2.44 \\
\hline
\end{tabular}

TB-LAMP loop-mediated isothermal amplification assay for tuberculosis 


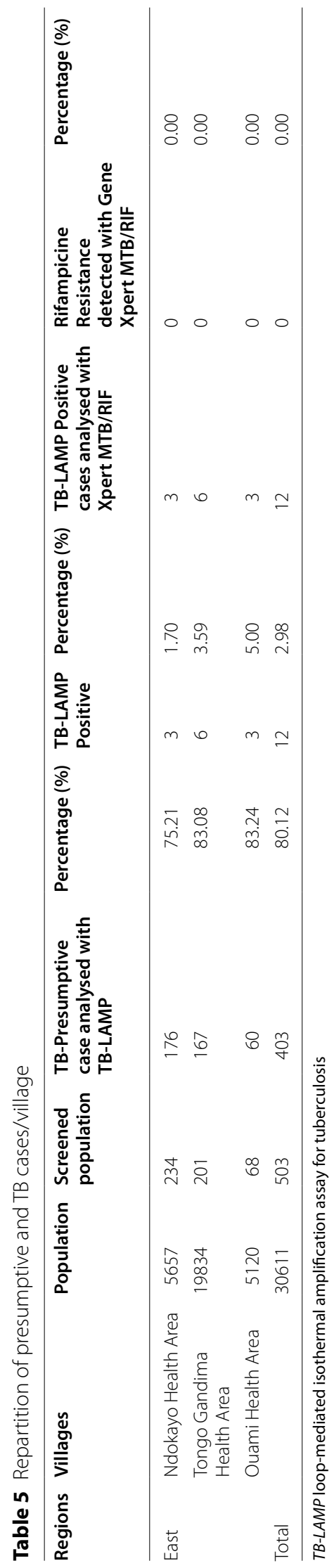


uncertainty analysis. Sensitivity and uncertainty analysis are important as they examine the effect of changing assumptions and cost elements over time. In our cost assessment, we assumed that there will be no change in the cost of the elements considered. The unit priced for most TB reagents or consumables has remained fixed for a while now. For example, the Gene Xpert cartridge is still sold at the same price of 9.98USD since 2012 when the test was introduced for routine diagnosis in Cameroon. Secondly, we were unable to determine the actual time it took from sample collection to results for each of the mass screening campaigns. All the mass screening campaigns did mention a time for sample collection but failed to capture when results were transmitted. Our TAT analysis was solely based on the generally accepted time it takes to process a sputum sample using the equipment.

\section{Conclusions}

This study demonstrated the advantages of the new algorithm for $\mathrm{TB}$ mass screening campaigns using TB-LAMP as initial diagnostic tool followed by Xpert MTB/RIF assays for all positive TB-LAMP samples. This algorithm improves early and rapid TB detection and drug resistance with respect to the TAT during $\mathrm{TB}$ mass-screening campaigns in prisons and villages with refugee camps. In addition, these assays used in combination were cost saving and shortens the time leading to anti-TB treatment initiation. Our study strongly acclaims the routine use of TB-LAMP and Xpert MTB/ RIF assays in combination for TB diagnosis and MDRTB which can substantially reduce the cost of the analysis from the second year of implementation. However, an adequate sample transport system should be implemented.

\footnotetext{
Abbreviations

TB: Tuberculosis; PTB: Pulmonary TB; TAT: Turnaround time; RR: Rifampicin resistance; NTCP: National Tuberculosis Control Program; DTCs: Diagnosis and Treatment Centers; NRL-TB: National Reference Laboratory; WRD: WHO-recommended rapid diagnostic.
}

\section{Supplementary Information}

The online version contains supplementary material available at https://doi. org/10.1186/s12879-022-07157-0.

Additional file 1. Estimation cost of each testing algorithms for three consecutive years.

\section{Acknowledgements}

The research team would like to thank all the medical staff of prisons and villagers, for presumptive tuberculosis cases screening and sputum samples collection. Thanks also to the laboratory technicians for samples analysis and to the Global Fund for providing necessary funds to organize these TB mass screening campaigns.

\section{Authors' contributions}

VFDD conceived and designed of the intellectual content, performed the experiments, conducted the primary analysis and wrote the manuscript; JBTM conducted the analysis and reviewed the manuscript; SE designed of the intellectual content, edited and reviewed manuscript, AKK and FBA collected data from prisons; NNA edited and reviewed manuscript; SMO conducted samples collection in villages, designed tables used in the manuscript; YJD and YKS performed laboratory analysis; MMT conducted samples collection in prisons as well as samples transportation to the laboratories; $\mathrm{VM}$ and $\mathrm{EMAB}$ designed the methodology and edited the manuscript. All authors reviewed the data analysis and approved the final manuscript.

\section{Funding}

Global Fund through the National Control Tuberculosis Program of Cameroon provided funds to conduct the mass screening campaign. However, the Global Fund had no role in the design of the study and collection, analysis, and interpretation of data and in writing the manuscript.

\section{Availability of data and materials}

The datasets used and/or analysed during the current study are available from the corresponding author on reasonable request.

\section{Declarations}

\section{Ethics approval and consent to participate}

Mass screening of TB at prisons and refugee camps by the National Tuberculosis Control Program in Cameroon is supported and approved by the Ministry of Public Health and Ministry of Justice, Department of Prisons Administration. The letters numbers 102/L/DRAPC/SSSP/BPS/2020 and 246/NS/MINSANTE/ SG/DLMEP/CNLT/DRSPC/GTR-TB-CE are approval letters from the Ministry of Justice, Department of Prisons Administration that authorize prison campaigns and the Ministry of Public Health through the National Tuberculosis Control Program in Cameroun, respectively for the Centre Region. A verbal informed consent was obtained from all participants. The ethics committee approved this procedure because the mass screening campaign had become a routine TB diagnostic procedures for prisons in order to help in detection of pulmonary TB cases missed by the other active screening methods. This study was conducted according to the guidelines of the Declaration of Helsinki. The database used in this study was pseudonymized before being used and all precautions were taken to avoid any risk of patient identification".

\section{Consent for publication}

Not applicable.

\section{Competing interests}

The authors declare that they have no competing interests.

\section{Author details}

${ }^{1}$ Mycobacteriology Unit, National Tuberculosis Reference Laboratory, Centre Pasteur du Cameroun, P.O. 1274, Yaoundé, Cameroon. ${ }^{2}$ Epidemiology and Public Health Unit, Centre Pasteur du Cameroun, Yaoundé, Cameroon. ${ }^{3}$ National Tuberculosis Control Program, Yaoundé, Cameroon.

Received: 2 May 2021 Accepted: 15 February 2022

Published online: 04 March 2022

\section{References}

1. WHO. Global Tuberculosis Report. 2019. https://apps.who.int/iris/bitst ream/handle/10665/329368/9789241565714-eng.pdf. Accessed 19 May 2020.

2. Lönnroth K, Corbett E, Golub J, Godfrey-Faussett P, Uplekar M, Weil D, et al. Systematic screening for active tuberculosis: rationale, definitions and key considerations. Int J Tuberc Lung Dis. 2013;17(3):289-98.

3. WHO. Systematic screening for active tuberculosis Principles and recommendations. 2013. https://apps.who.int/iris/bitstream/handle/10665/ 84971/9789241548601_eng.pdf. 
4. Gurbanova E, Mehdiyev R, Blondal K, Altraja A. Rapid tests reduce the burden of tuberculosis in Azerbaijan prisons: special emphasis on rifampicinresistance. Rev Espanola Sanid Penit. 2018;20(3):111-20.

5. Noeske J, Ndi N, Mbondi S. Controlling tuberculosis in prisons against confinement conditions: a lost case? Experience from Cameroon. Int J Tuberc Lung Dis. 2011;15(2):223-7.

6. O'Grady J, Hoelscher M, Atun R, Bates M, Mwaba P, Kapata N, et al. Tuberculosis in prisons in sub-Saharan Africa-the need for improved health services, surveillance and control. Tuberc Edinb Scotl. 2011;91(2):173-8.

7. Busatto C, de Nunes LS, de Valim ARM, Valença MS, Krug SF, Becker D, et al. Tuberculosis among prison staff in Rio Grande do Sul. Rev Bras Enferm. 2017;70(2):370-5.

8. Reis AJ, de David SMM, de Nunes LS, de Valim ARM, Possuelo LG. Recent transmission of drug-resistant Mycobacterium tuberculosis in a prison population in southern Brazil. J Bras Pneumol. 2016;42(4):286-9.

9. Niveau G. Prevention of infectious disease transmission in correctional settings: a review. Public Health. 2006;120(1):33-41.

10. National Tuberculosis Control Program. 2020 Cameroun National TB Evaluation report. 2021.

11. Noeske J, Ndi N, Elo GA, Mfondih SM. Tuberculosis incidence in Cameroonian prisons: a 1-year prospective study. South Afr Med J S. 2014;104(3):209-11.

12. WHO. Cameroon TB Profile. 2018. Available on: https://www.who.int/tb/ country/data/profiles/en/.

13. Stop TB Partnership. Strategies for effective TB case finding in prisons and closed settings [Internet]. 2018. available on: https://stoptb-strategicinitia tive.org/elearning/wp-content/uploads/2019/04/STBFG_02.pdf.

14. Masoud D, Malgosia G, Michael EK, Hernan R, Andrey Z. Guidelines for Control of Tuberculosis in Prisons. 2009. Available on https://www.resea rchgate.net/publication/281115087_Guidelines_for_the_Control_of_TB_ in_Prisons.

15. Masoud D, Dato C, Pierpaolo de Colombani C. TB prevention and control care in prisons. 2014. Available on: https://www.medbox.org/document/ tb-prevention-and-control-care-in-prisons\#GO.

16. Harries AD, Kumar AMV. Challenges and Progress with Diagnosing Pulmonary Tuberculosis in Low- and Middle-Income Countries. Diagnostics. 2018. https://www.ncbi.nlm.nih.gov/pmc/articles/PMC6315832/ Accessed 14 Apr 2020;8(4).

17. WHO. Automated Real-time Nucleic Acid Amplification Technology for Rapid and Simultaneous Detection of Tuberculosis and Rifampicin Resistance: Xpert MTB/RIF System. 2011. Available from: http://whqlibdoc.who. int/publications/2011/9789241501545_eng.pdf.

18. WHO. The use of loop-mediated isothermal amplifi cation (TB-LAMP) for the diagnosis of pulmonary tuberculosis [Internet]. 2016 p. 52. Available on: https://www.finddx.org/wp-content/uploads/2016/08/WHO-Guida nce-on-TB-LAMP-2016.pdf.

19. Nakiyingi L, Nakanwagi P, Briggs J, Agaba T, Mubiru F, Mugenyi M, et al. Performance of loop-mediated isothermal amplification assay in the diagnosis of pulmonary tuberculosis in a high prevalence TB/HIV rural setting in Uganda. BMC Infect Dis. 2018;18. Available on https://www. ncbi.n/m.nih.gov/pmc/articles/PMC5822669.

20. Donfack VF, Ngando L, Pefura EW, Che DS, Ateba G, Bigna JJ, et al. Comparative study of LoopampTM Mycobacterium tuberculosis complex kit for rapid detection of Mycobacterium tuberculosis complex in cameroon. Biomed Biotechnol Res J. 2018;2:46-52.

21. Priya BS, Katherine F, Luke S, Christen MG, Adithya C. Diagnostic accuracy of TB-LAMP for pulmonary tuberculosis: a systematic review and metaanalysis. BMC Infect Dis. 2019;19:268

22. Cameroon World Prison Brief. Available on: https://www.prisonstudies. org/country/cameroon.

23. Global Laboratory Initiative. GLI Practical Guide to TB Laboratory Strengthening. 2017. http://www.stoptb.org/wg/gli/assets/documents/ GLI_practical_guide.pdf: http.

24. Levin HM, McEwan PJ. Cost-effectiveness analysis: methods and applications. 2nd ed. Thousand Oaks: Sage Publications; 2001.

25. Ndlovu Z, Fajardo E, Mbofana E, Maparo T, Garone D, Metcalf C, et al. Multidisease testing for HIV and TB using the GeneXpert platform: A feasibility study in rural Zimbabwe. PLoS ONE. 2018;13(3):e0193577.

26. Global Drug Facility (GDF). Diagnostics Catalog 2018. Available on http:// www.stoptb.org/assets/documents/gdf/Diagnostics_Catalog_2018_ WEB.pdf.
27. TB-LAMP test now available for $\$ 6$ through Global Drug Facility. 2020 Available in the GDF diagnostics catalog. HumaLoop T

28. Global Drug Facility (GDF). LOOPAMPTM (LAMP) Test, Technical Information Note. 2020. Available on http://www.stoptb.org/assets/documents/ gdf/drugsupply/LAMP_info_note.pdf.

29. WHO. Tuberculosis Control in Prisons, a Manual for Programme Managers. 2000:172. Available on: https://apps.who.int/iris/handle/10665/66823.

\section{Publisher's Note}

Springer Nature remains neutral with regard to jurisdictional claims in published maps and institutional affiliations.
Ready to submit your research? Choose BMC and benefit from:

- fast, convenient online submission

- thorough peer review by experienced researchers in your field

- rapid publication on acceptance

- support for research data, including large and complex data types

- gold Open Access which fosters wider collaboration and increased citations

- maximum visibility for your research: over $100 \mathrm{M}$ website views per year

At BMC, research is always in progress.

Learn more biomedcentral.com/submissions 